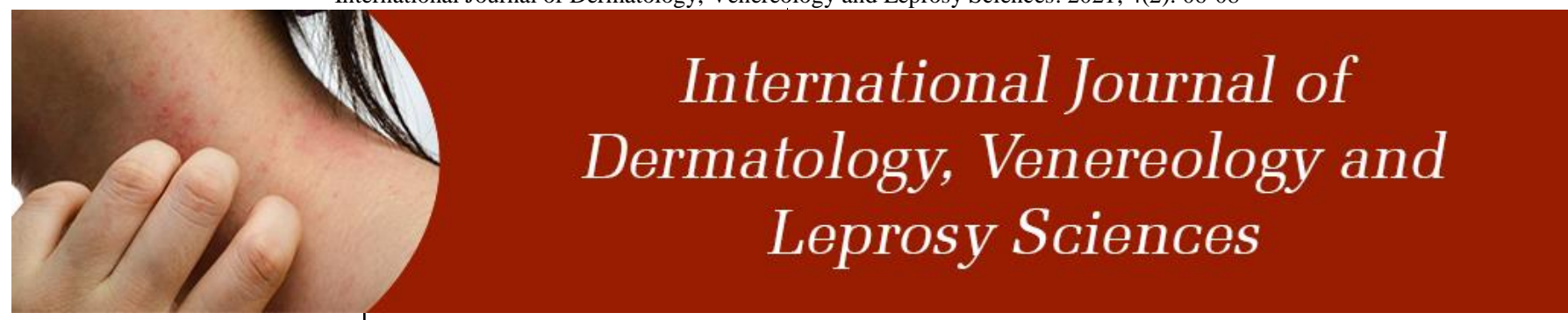

E-ISSN: 2664-942X

P-ISSN: 2664-9411

www.dermatologypaper.com

Derma 2021; 4(2): 06-08

Received: 03-01-2020

Accepted: 07-03-2021

Dr. Shwetha V Rajiv

Assistant Professor,

Department of Dermatology,

Malabar Medical College,

Modakkallur, Calicut, Kerala, India

\section{To study the Clinico epidemiological profile of pityriasis rosea in a tertiary care Hospital in North Kerala}

\section{Dr. Shwetha V Rajiv}

DOI: https://doi.org/10.33545/26649411.2021.v4.i2a.79

\begin{abstract}
Pityriasis rosea (PR) is a relatively common self-limiting papulosquamous disorder, characterized by acute onset of a large scaly, erythematous plaque (herald plaque) followed by several smaller lesions distributed along the lines of cleavage on the trunk and extremities (secondary eruptions). The approximate incidence of PR is $0.5-2 \%$ and affects people of both sexes in 15-30 years age group although also seen commonly in elderly and children. ${ }^{2}$ Spontaneous resolution is seen within 6-8 weeks but may be earlier or delayed until 3-6 months Numerous hypotheses have been postulated about the exact cause of PR, incriminating both non infective agents such as viruses, bacteria, spirochetes, and no infective etiologies such as atopy and autoimmunity. The distinctly programmed clinical course, lack of recurrence for most of the patients, seasonal variation, and clustering of cases provide evidence in favour of an infective etiology, probably viral. However a conclusive infectious cause has not yet been identified. In this background, we set out to describe the various clinical pattern of the disease, epidemiologic factors among patients encountered in out-patients attending dermatology department in our locality and to compare the results with the present literature.
\end{abstract}

Keywords: Clinico-epidemiological, profile, pityriasis rosea

\section{Introduction}

Pityriasis rosea (PR) is a relatively common self-limiting papulosquamous disorder, characterized by acute onset of a large scaly, erythematous plaque (herald plaque) followed by several smaller lesions distributed along the lines of cleavage on the trunk and extremities (secondary eruptions) ${ }^{[1]}$. The approximate incidence of PR is $0.5-2 \%$ and affects people of both sexes in 15-30 years age group although also seen commonly in elderly and children [2]. Spontaneous resolution is seen within 6-8 weeks but may be earlier or delayed until 3-6 months Numerous hypotheses have been postulated about the exact cause of PR, incriminating both infective agents such as viruses, bacteria, spirochetes, and no infective etiologies such as atopy and autoimmunity ${ }^{[2]}$. The distinctly programmed clinical course, lack of recurrence for most of the patients, seasonal variation, and clustering of cases provide evidence in favour of an infective etiology, probably viral. However a conclusive infectious cause has not yet been identified ${ }^{[3]}$.

Atypical manifestations in Pityriasis Rosea include variation in morphology, distribution and symptoms. The various atypical morphology described in literature are vesicular, purpuric, Urticarial, generalised papular, lichenoid, erythema multiforme like, follicular, giant, exfoliative dermatitis and atypical herald patch. Atypical distribution described are inverse, acral, blaschkoid, unilateral, limb-girdle, oral mucosal and localised type ${ }^{[2]}$. Pruritus is absent in only about quarter of cases whereas lesions can be extremely pruritic in a variant known as PR irritata ${ }^{[4]}$.

Diagnosis of PR is made based on detailed history of clinical events, including history of prodrome and upper respiratory tract infection and careful clinical examination to identify herald patch, collarette scales on at least two secondary lesions. In cases of diagnostic dilemma, we sought for skin biopsy though histopathology features are fairly nonspecific. southern part of India ${ }^{[8,9]}$. There are two studies in literature regarding the association of streptococcal infection with Pityriasis rosea however the results were conflicting ${ }^{[10,11]}$. In this background, we set out to describe the various clinical pattern of the disease,
Corresponding Author: Dr. Shwetha V Rajiv Assistant Professor, Department of Dermatology, Malabar Medical College, Modakkallur, Calicut, Kerala, India 
epidemiologic factors among patients encountered in outpatients attending dermatology department in our locality and to compare the results with the present literature.

\section{Materials and methods}

1. To study the various clinical presentations of Pityriasis rosea

2. To identify the epidemiological factors associated with Pityriasis rosea

\section{Inclusion criteria}

All patients attending dermatology outpatient department with clinical signs and symptoms suggestive of Pityriasis rosea during 1 year period (Average number of Pityriasis Rosea cases in the OP per year-100).

\section{Exclusion criteria}

1. Patients who do not give consent for the study

2. VDRL positive patients

\section{Study setting}

Dermatology OPD of Malabar Medical College, Modakkallur, Kozhikode

\section{Type of study}

Observational study

\section{Methodology}

Patients presenting to Dermatology department with clinical signs and symptoms of Pityriasis rosea and those who are willing to give consent will be included in the study. A detailed history and clinical findings will be recorded as per a preset proforma. Investigations including skin biopsy, Venereal disease research laboratory (VDRL) and $\mathrm{KOH}$ examination will be done in doubtful cases to exclude other diseases that may have similar presentation. All clinical findings will be recorded and stored. Data will be entered and tabulated using Microsoft Excel. Statistical analysis will be done using SPSS software.

\section{Results}

Table 1: Age Distribution

\begin{tabular}{|c|c|}
\hline Age Group & No of Patients \\
\hline $10-20$ years & 09 \\
\hline $21-30$ years & 08 \\
\hline $31-40$ years & 19 \\
\hline $41-50$ years & 04 \\
\hline $51-60$ years & 20 \\
\hline
\end{tabular}

Table 2: Sex Distribution

\begin{tabular}{|c|c|}
\hline Male & 18 \\
\hline Female & 42 \\
\hline
\end{tabular}

Table 4: Occupation

\begin{tabular}{|c|c|}
\hline Manual & $\mathbf{1 9}$ \\
\hline Office & 21 \\
\hline Household & 17 \\
\hline Other & 03 \\
\hline
\end{tabular}

Table 5: H/o Itching

\begin{tabular}{|c|c|}
\hline Itching history & \\
\hline Yes & 21 \\
\hline No & 39 \\
\hline
\end{tabular}

Table 6: H/o Respiratory infection

\begin{tabular}{|c|c|}
\hline Yes & 16 \\
\hline No & 44 \\
\hline
\end{tabular}

Table 7: H/o simimilar infections in neighborhood

\begin{tabular}{|c|c|}
\hline Yes & 07 \\
\hline No & 53 \\
\hline
\end{tabular}

Table 8: Morphology of skin lesions of patients

\begin{tabular}{|c|c|}
\hline Typical & $\mathbf{5 3}$ \\
\hline Papular & 01 \\
\hline Erythema multiforme - like & 02 \\
\hline papulovesicular & 01 \\
\hline psoriasiform & 02 \\
\hline eczimatous & 01 \\
\hline
\end{tabular}

Table 9: Treatment

\begin{tabular}{|c|c|}
\hline Azythromycin & 60 \\
\hline Topical steroids & 60 \\
\hline Oral steroids & 03 \\
\hline
\end{tabular}

Table 10: Review after 2 weeks

\begin{tabular}{|c|c|}
\hline Cured & 37 \\
\hline Not cured but decreased manifestation & 23 \\
\hline
\end{tabular}

\section{Discussion}

$\mathrm{PR}$ is a common disease reported in all races with an incidence of 6.8 per 1000 dermatological patients. Cutaneous adverse drug reaction profile from a tertiary care outpatient setting in Eastern India has reported an incidence of PR-like skin rash as $1.89 \%$ during the study period of 1 year. According to studies, the overall male-to-female ratio is $1: 1.5$. PR may occur in patients of all ages; however, approximately $75 \%$ of cases occur between the ages of 10 and 35 years. It is rare in both the very young (less than 2 years) and the elderly (more than 65 years). Recurrences of PR are rare, which suggests lasting immunity after an initial episode of PR. In our study, none of the patients had history of similar lesions in the past. Up to $69 \%$ of patients with PR have a prodromal illness before the herald patch appears. In our patients, only $27.5 \%$ patients had a history of prodromal symptoms. Pruritus is severe in $25 \%$ of patients with uncomplicated PR, slight to moderate in 50\%, and absent in $15 \%$. About $75 \%$ of patients in our study had associated pruritus. In a minority of patients, flu-like symptoms have been reported, including general malaise, headache, nausea, loss of apetite, fever, and arthralgia's. A history of a herald patch and a few characteristic lesions in a "Christmas tree" pattern aid the diagnosis of typical PR. Herald patch is seen in $50 \%-90 \%$ of cases. In our study, only $35 \%$ had herald patch. Ganguly had observed herald patch in approximately $92 \%$ of patients of PR. In one series, only $17 \%$ of patients referred to a dermatology clinic reported a herald patch. 
Atypical variants of PR are rare and occur in only $20 \%$ of cases. PR can be atypical with respect to morphology, size, distribution, number, site, and course of disease. The various atypical morphological types include vesicular, purpurea, urticarial, generalized popular, lichenoid, erythrodermic, and EM-like PR.

\section{Conclusion}

The clinicoepidemiological profile of pityriasis rosea in a tertiary care hospital in north Kerala has been done successfully.

\section{References}

1. Zawar V, Jerajani H, Pol R. Current trends in pityriasis rosea, Expert Rev Dermatol. 2010;5:32533.

2. Mahajan K, Relhan V, Relhan AK, Garg VK. Pityriasis rosea: An update on etiopathogenesis and management of difficult aspects, Indian J Dermatol. 2016;61:375-84

3. Bjornberg A, Tegner E. Pityriasis Rosea, In: Fitzpatrick TB, Freedberg IM, Eisen AZ et al. eds. Dermatology in General Medicine, 5th ed, New York: McGraw Hill, 1999, 541-6.

4. González LM, Allen R, Janniger CK, Schwartz RA. Pityriasis rosea: An important papulosquamous disorder, Int J Dermatol. 2005;44:757-64.

5. Khare S, Nagar R, Singh S. Clinico-epidemiological study of pityriasis rosea in children. International Journal of Medical Research and Review. 2015;3(11):1339-1344.

6. Yusuf SM, Tijjani UA, Nashabaru I, Saidu H, Gezawa ID, Mijinyawa MS. One-year review of pityriasis rosea among outpatients in Kano, Northwestern Nigeria, Niger J Basic Clin Sci. [serial online] 2018, [cited 2019 Sep 26];15:77-80.

7. Chhabra N, Prabha N, Kulkarni S, Ganguly S. Pityriasis rosea: Clinical profile from Central India, Indian Dermatology Online Journal. [serial online] 2018, [cited 2019 Sep 25];9:414-7.

8. Kambil SM. Pityriasis rosea: a clinicoepidemiological study of 115 cases, International Journal of Research in Dermatology. 2018;4(2):202-204.

9. Raikar D. Clinical profile of pityriasis rosea: A descriptive study from urban Karnataka. 2019;5(3):1.

10. Sharma PK, Yadav TP, Gautam RK, Taneja N, Satyanarayana L. Erythromycin in pityriasis rosea: A double-blind, placebo-controlled clinical trial, J Am Acad Dermatol. 2000;42(2 Pt 1):241-4.

11. Parija M, Thappa DM. Study of role of streptococcal throat infection in pityriasis rosea, Indian J Dermatol. 2008;53:171-3. 